Article

\title{
Revisiting the Formation and Tunable Dissociation of a [2]Pseudorotaxane Formed by Slippage Approach
}

\author{
Ken Cham-Fai Leung ${ }^{1,2, *}$, Kwun-Ngai Lau ${ }^{3}$ and Wing-Yan Wong ${ }^{3}$ \\ 1 Department of Chemistry and Institute of Creativity, The Hong Kong Baptist University, \\ Kowloon Tong, Kowloon, Hong Kong, China \\ 2 Institute of Molecular Functional Materials, University Grants Committee, Hong Kong, China \\ 3 Department of Chemistry, The Chinese University of Hong Kong, Shatin, NT, Hong Kong, China; \\ E-Mails: terrylau1036@gmail.com (K.-N.L.); Wingwong.wwy@gmail.com (W.-Y.W.) \\ * Author to whom correspondence should be addressed; E-Mail: cfleung@hkbu.edu.hk; \\ Tel.: +852-3411-2319; Fax: +852-3411-7348.
}

External Editor: John Hardy

Received: 26 March 2015 / Accepted: 10 April 2015 / Published: 13 April 2015

\begin{abstract}
A new [2]pseudorotaxane DB24C8 $\supset$ 1-H·PF6 with dibenzo[24]crown-8 (DB24C8) crown ether-dibenzylammonium $\left(\mathbf{1}-\mathrm{H} \cdot \mathrm{PF}_{6}\right)$ binding which was formed by slippage approach at different solvents and temperature, had been isolated and characterized by NMR spectroscopy and mass spectrometry. The [2]pseudorotaxane DB24C8 $\supset$ 1-H $\cdot \mathrm{PF}_{6}$ was stable at room temperature. The dissociation rate of [2]pseudorotaxane DB24C8 $\supset \mathbf{1}-\mathrm{H} \cdot \mathrm{PF}_{6}$ could be tuned by using different stimuli such as triethylamine (TEA)/diisopropylethylamine (DIPEA) and dimethyl sulfoxide (DMSO). In particular, the dissociation of [2]pseudorotaxane DB24C8 $\supset 1-H \cdot P F 6$ by an excess of TEA/DIPEA base mixture possessed a long and sustained, complete dissociation over 60 days. Other stimuli by DMSO possessed a relatively fast dissociation over $24 \mathrm{~h}$.
\end{abstract}

Keywords: rotaxane; thermodynamic synthesis; dissociation; slippage; crown ether

\section{Introduction}

Rotaxanes contain a linear dumbbell-shaped component bearing bulky end-groups or stoppers around which one or more macrocycles are trapped. On the other hand, pseudorotaxanes are 
temporally encircled around an unstoppered thread through noncovalent interactions from which they are readily susceptible to dissociation without breaking a covalent bond [1-4]. Rotaxanes and pseudorotaxanes have been studied extensively for the ability of the interlocked ring to be switched on demand by external stimuli such as $\mathrm{pH}[5,6]$, electrochemical reagents [7], heat [8,9], moisture [10,11], salt [12], light [13], etc. Coupled with their ability to be customized and optimized for nanoscale functions, these interlocked molecules are excellent candidates as movable elements in the construction of nanovalves [14] based on a porous, solid-phase support, for controlled substrate release. Many examples have been demonstrated about their relatively fast substrate releases within $24 \mathrm{~h}$ by tuning the $\mathrm{pH}$ values in the solution [12]. Currently, no pseudorotaxane or rotaxane building blocks are available and suitable for the construction of vehicles for sustained substrate release over a week.

The construction of rotaxane-like assemblies has recently relied upon thermodynamic, templated reactions with enhanced efficiencies [15-24]. The term "slippage" has been coined [25-28] for pseudorotaxane synthesis that employs thermodynamic threading of macrocycle to a "dumbbell". This strategy utilizes (1) the size complementarily between the macrocycle and the "dumbbell's" stoppers; and (2) the stabilizing noncovalent bonding interactions between the macrocycle and the "dumbbell's" rod. In this strategy, the macrocycle and the dumbbell have been separately synthesized, prior to heating them together in solution so that the free energy of activation for the thermodynamic threading (slippage) of macrocycle to dumbbell can be overcome. The presence of a template on the dumbbell's rod renders the pseudorotaxane structure more stable so that the free energy of activation for its dissociation becomes insurmountable when the solution has been cooled to ambient temperature. There are several disadvantages of the slippage approach in terms of reaction time and stability. Generally, it requires a long reaction time with a large slippage rate $\left(k_{\mathrm{on}}\right)$ for pseudorotaxane formation from usually a few days up to 90 days [27]. However, the dissociation of pseudorotaxane will sometimes have an uncontrollable, small slippage rate $\left(k_{\text {off }}\right)$. Therefore, there is a need to study a better reaction condition for pseudorotaxane formation by slippage and to tune the pseudorotaxane dissociation rate ( $\left.k_{\text {off }}<<k_{\text {on }}\right)$ from days to hours.

\section{Results and Discussion}

Herein, we employ a slippage approach in one pot (Figure 1) to yield a thermodynamically stable [2]pseudorotaxane [29,30] by mixing an ammonium thread (dumbbell) $\mathbf{1}-\mathrm{H} \cdot \mathrm{PF} 6$ with dibenzo[24]crown-8 (DB24C8). Benzo-crown ether DB24C8 is capable to recognize with secondary ammonium ions by virtue of $\left[\mathrm{N}^{+}-\mathrm{H} \cdots \mathrm{O}\right]$ and $\left[\mathrm{N}^{+}-\mathrm{C}-\mathrm{H}^{\cdots} \mathrm{O}\right]$ hydrogen bonds, electrostatic interactions, and augmented with some aromatic $\pi-\pi$ interactions [31-36]. The 3,5-dimethoxyaryl moiety at one end of the dumbbell $1-\mathrm{H} \cdot \mathrm{PF}_{6}$, is a relatively bulky stopper that can effectively block the passageway of DB24C8 at high reaction temperature. On the other hand, the cyclohexyl ring of the dumbbell-like thread, in contrast, allow the crown ether to thread through to the dumbbell's rod at elevated reaction temperature with the molecular flipping of between their chair-boat-chair forms [31-37]. 


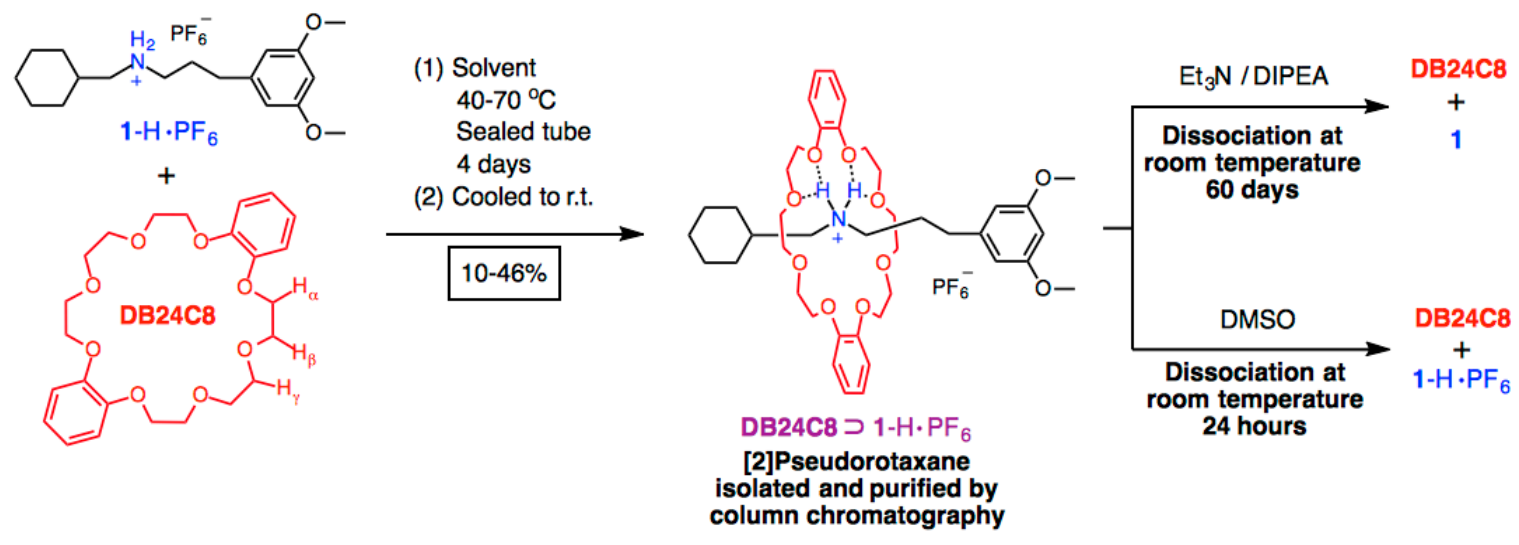

Figure 1. Molecular structures of the crown ether DB24C8 and the ammonium thread "dumbbell" 1-H·PF 6 . The 3,5-dimethoxyaryl group of the thread acts as an effective stopper to prevent the extrusion of macrocycle while the cyclohexyl group of the thread allows the slipping of macrocycle upon heating in selected solvents. The thermodynamically stable [2]pseudorotaxane DB24C8 $\supset \mathbf{1}-\mathrm{H} \cdot \mathrm{PF}_{6}$ was isolated and subjected to dissociation studies with excess amine base (Et ${ }_{3} \mathrm{~N}$ and DIPEA) mixture and dimethyl sulfoxide (DMSO).

The reaction time of the pseudorotaxane synthesis was fixed in 4 days with reasonable yields ( $\sim 50 \%)$. The percentage yields (Table 1) of individual [2]pseudorotaxane after a reaction time of 4 days, have been determined by ${ }^{1} \mathrm{H}$ NMR spectroscopy according to their "bound" and "free" signal intensities [36-38]. From the results, the reaction yields and rates in synthesizing the [2]pseudorotaxanes are sensitive to different solvents and temperatures. In particular, the percentage yield of the [2]pseudorotaxane $\mathbf{D B 2 4 C 8} \supset \mathbf{1}-\mathrm{H} \cdot \mathrm{PF}_{6}$ was found to be the highest (46\%) after a reaction temperature at $70{ }^{\circ} \mathrm{C}$ with $\mathrm{MeCN}$ compared to using $\mathrm{PhMe}\left(70{ }^{\circ} \mathrm{C}\right)$ and $\mathrm{CH}_{2} \mathrm{Cl}_{2}\left(40{ }^{\circ} \mathrm{C}\right)$. This is partially because, in polar solvents, the [2]pseudorotaxane might undergo intra and/or intermolecular aggregation of the hydrophobic alkyl chains and this will overcome the extrusion effect. The [2]pseudorotaxane DB24C8 $\supset \mathbf{1}-\mathrm{H} \cdot \mathrm{PF}_{6}$ could be isolated by flash chromatography on silica gel $\left(\mathrm{CH}_{2} \mathrm{Cl}_{2} / \mathrm{THF}=7 / 1\right)$ and characterized by NMR spectroscopy and mass spectrometry.

Table 1. Percentage yields of the [2]pseudorotaxanes after slippage reaction for 4 days.

Analyzed by ${ }^{1} \mathrm{H}$ NMR spectroscopy (400 MHz, $\left.298 \mathrm{~K}\right)$.

\begin{tabular}{|c|c|}
\hline Solvent (Reaction Temperature in Sealed Tube) & DB24C8つ1-H·PF 6 \\
\hline $\mathrm{MeCN}\left(70^{\circ} \mathrm{C}\right)$ & $46 \%$ \\
\hline $\operatorname{PhMe}\left(70^{\circ} \mathrm{C}\right)$ & $30 \%$ \\
\hline $\mathrm{CH}_{2} \mathrm{Cl}_{2}\left(40{ }^{\circ} \mathrm{C}\right)$ & $10 \%$ \\
\hline
\end{tabular}

${ }^{1} \mathrm{H}$ NMR spectroscopy was employed to evaluate the structural features of [2]pseudorotaxanes. By way of an example, the isolated and pure [2]pseudorotaxane DB24C8 $\supset$ 1-H $\cdot \mathrm{PF}_{6}$ reveals (Figure 2) proton chemical shifts of the $-\mathrm{CH}_{2} \mathrm{NH}_{2}{ }^{+} \mathrm{CH}_{2}$ - moieties at $\delta=3.14$ and 3.32 ppm (bound), comparing to the $-\mathrm{CH}_{2} \mathrm{NH}_{2}{ }^{+} \mathrm{CH}_{2}-$ moieties of its thread $1-\mathrm{H} \cdot \mathrm{PF}_{6}$ at $\delta=2.81$ and $3.06 \mathrm{ppm}$ (free). 


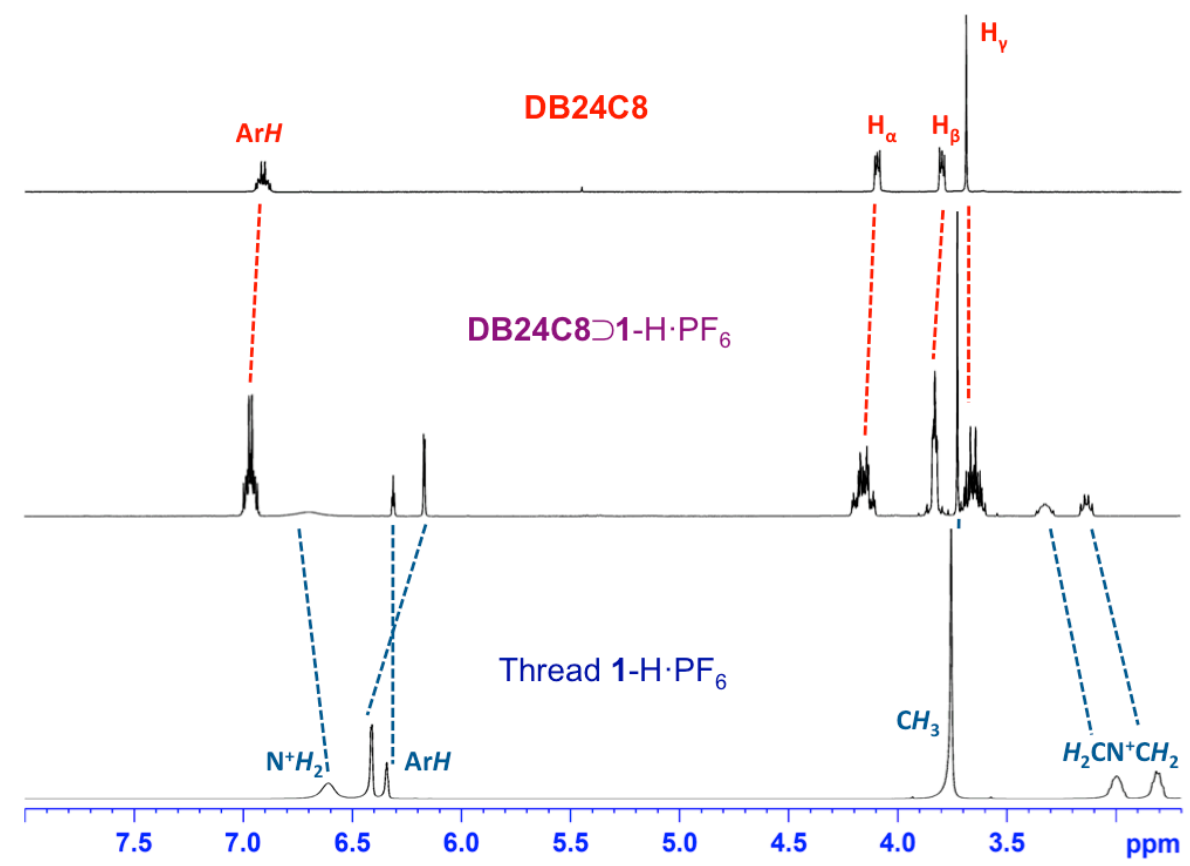

Figure 2. Partial ${ }^{1} \mathrm{H}$ NMR spectra (400 MHz, CD 3 CN, $298 \mathrm{~K}$ ) of crown ether DB24C8, isolated pure [2]pseudorotaxane DB24C8 $\supset \mathbf{1}-\mathrm{H} \cdot \mathrm{PF}_{6}$, and ammonium thread $\mathbf{1}-\mathrm{H} \cdot \mathrm{PF}_{6}$.

High-resolution electrospray ionization mass spectrometry (ESI-MS) has been employed (Figure 3) to further characterize the [2]pseudorotaxane. The molecular ion peak at $\mathrm{m} / \mathrm{z} 740$ which is the most abundant peak in the spectrum, is corresponded to the $\left[\mathrm{M}-\mathrm{PF}_{6}\right]^{+}$ion of the [2]pseudorotaxane.

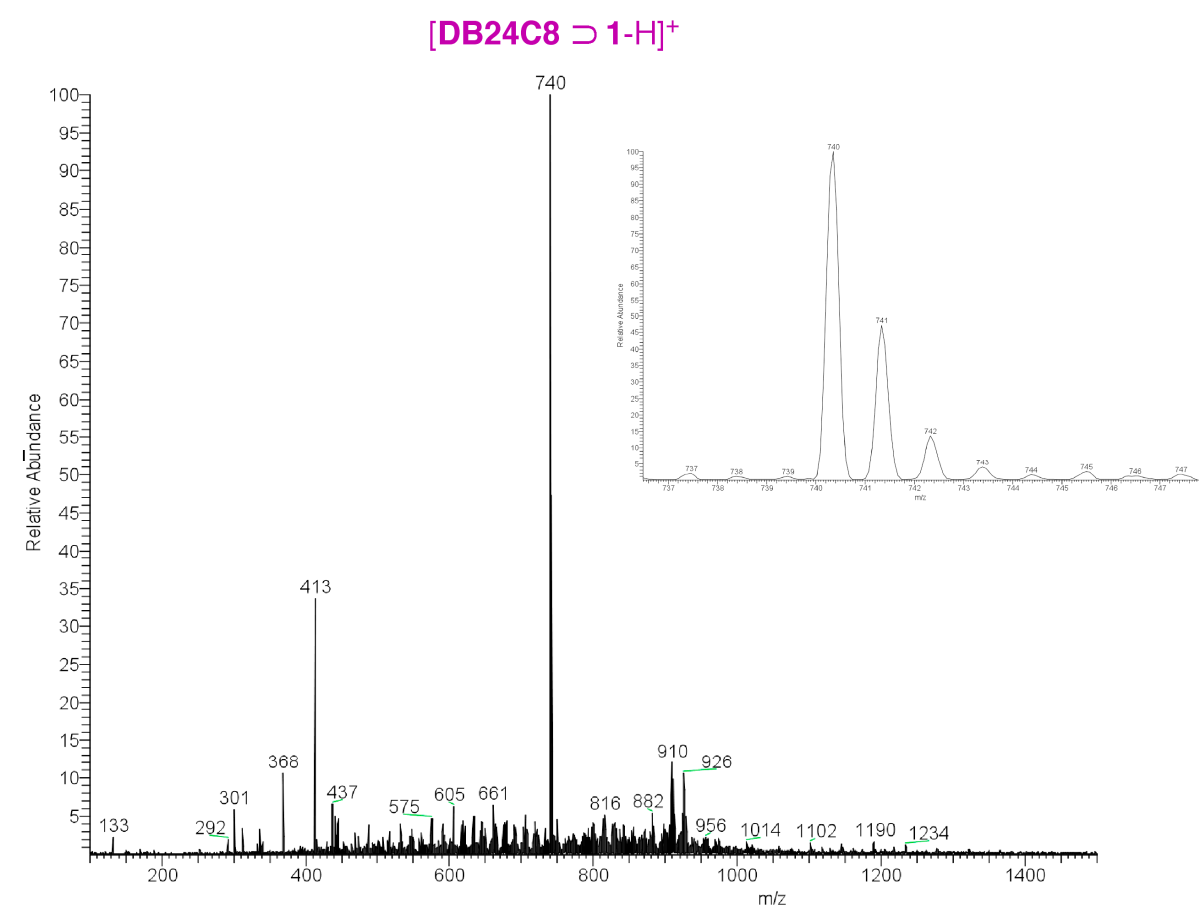

Figure 3. Electrospray ionization mass spectrometry (ESI-MS) of the [2]pseudorotaxane DB24C8 $\supset 1-\mathrm{H} \cdot \mathrm{PF}$, showing the molecular ion signal $[\mathrm{M}-\mathrm{PF} 6]^{+}$at $m / z 740$. 
Furthermore, the dissociation and stabilities of [2]pseudorotaxane towards organic amine bases and a hydrogen bond disrupting solvent were evaluated. In particular, pure [2]pseudorotaxane DB24C8 $\supset$ 1-H $\cdot \mathrm{PF}_{6}$ was dissolved in $\mathrm{CD}_{3} \mathrm{CN}$ and was treated with an excess of triethylamine (TEA)/diisopropylethylamine (DIPEA) mixture [5,6,12]. The ammonium ion of the thread $1-\mathrm{H}^{-} \mathrm{PF}_{6}$ could be successfully deprotonated by the bases wherein the DB24C8 loss its binding affinity towards the deprotonated, amine thread 1. Since the template effect is lost, the [2]pseudorotaxane is no longer stable whereas extrusion of macrocycle occurs with the molecular flipping of the cyclohexyl ring. This extrusion behavior was monitored (Figure 4) by observing a significant decrease of characteristic signal at $\delta=6.16 \mathrm{ppm}$ (bound $\mathrm{Ar} H$ of $1-\mathrm{H} \cdot \mathrm{PF}_{6}$ ) as well as an increase of signal at $\delta=6.38 \mathrm{ppm}$ (free $\mathrm{ArH}$ of 1) from their ${ }^{1} \mathrm{H}$ NMR spectra over time. Interestingly, the [2]pseudorotaxane requires almost 60 days to dissociate completely into two separate components at ambient temperature. The half-life of dissociation was determined to be approximately 2 days (Figure 6).

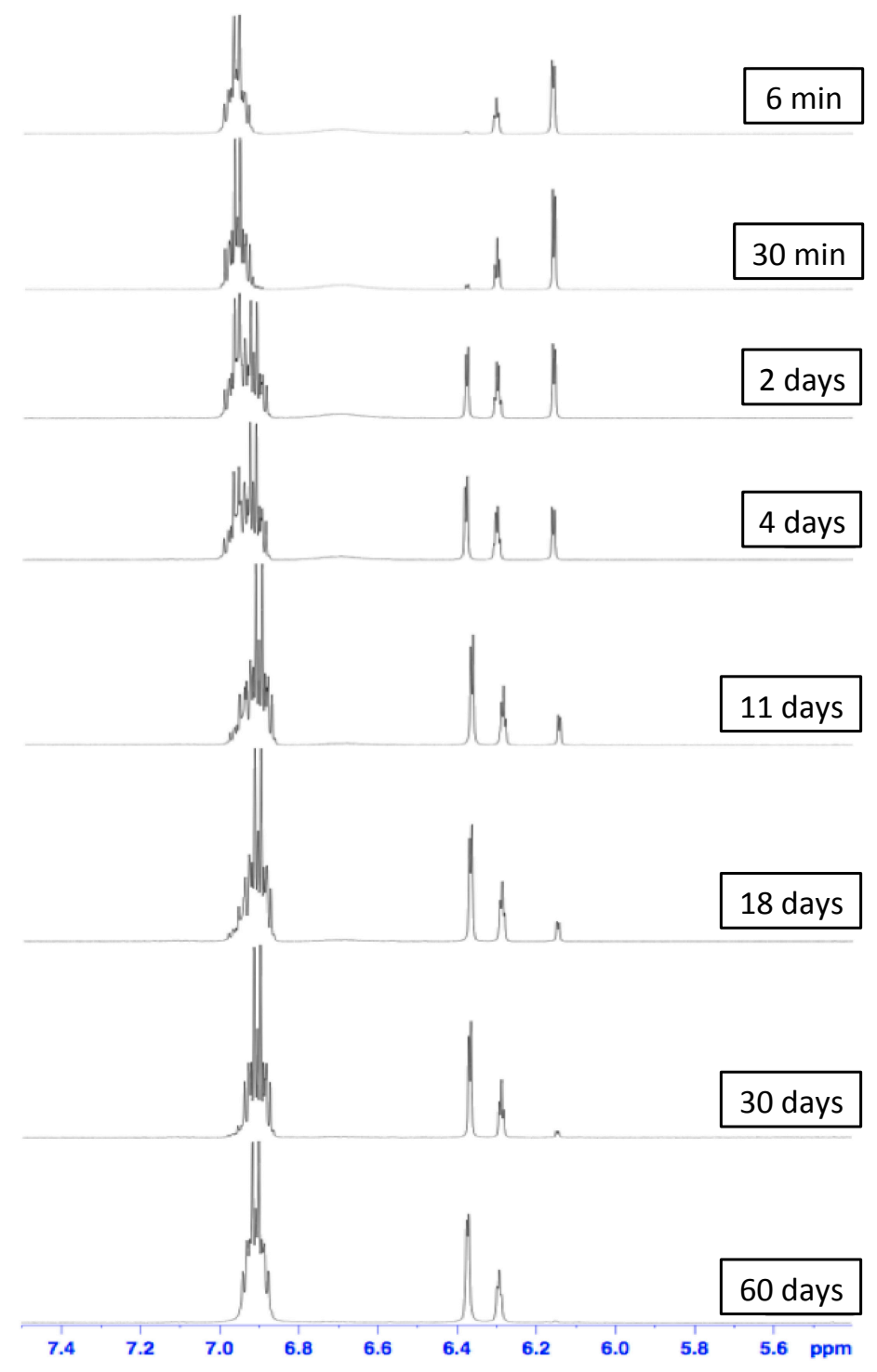

Figure 4. Partial ${ }^{1} \mathrm{H}$ NMR spectra $\left(400 \mathrm{MHz}, \mathrm{CD}_{3} \mathrm{CN}, 298 \mathrm{~K}\right)$ showing the extrusion of DB24C8 macrocycle from the isolated [2]pseudorotaxane DB24C8 $\supset$ 1-H $\cdot \mathrm{PF}_{6}$ with excess triethylamine (TEA)/diisopropylethylamine (DIPEA) mixture in $\mathrm{CD}_{3} \mathrm{CN}$ over time. 
On the other hand, by dissolving the pure [2]pseudorotaxane DB24C8 $\supset \mathbf{1}-\mathrm{H} \cdot \mathrm{PF} 6$ in a hydrogen bond disfavored solvent-dimethyl sulfoxide (DMSO) [1,27], extrusion of DB24C8 from the thread $1-\mathrm{H} \cdot \mathrm{PF}_{6}$ occurred. Since the template effect is lost, the [2]pseudorotaxane is no longer stable whereas extrusion of macrocycle occurs with the molecular flipping of the cyclohexyl ring. This extrusion behavior was monitored (Figure 5) by observing the decreases of characteristic signals at $\delta=3.81$, and $4.14 \mathrm{ppm}$ (bound $-\mathrm{OCH}_{2} \mathrm{CH}_{2} \mathrm{O}-$ of $\mathbf{D B 2 4 C 8}$ ) as well as the increases of signals at $\delta=3.74$, and $4.07 \mathrm{ppm}$ (free $-\mathrm{OCH}_{2} \mathrm{CH}_{2} \mathrm{O}$ - of DB24C8) from their ${ }^{1} \mathrm{H}$ NMR spectra (in DMSO- $d_{6}$ ) over time. The [2]pseudorotaxane required only $24 \mathrm{~h}$ for a complete dissociation. The half-life of dissociation was determined to be approximately $4 \mathrm{~h}$ (Figure 6).

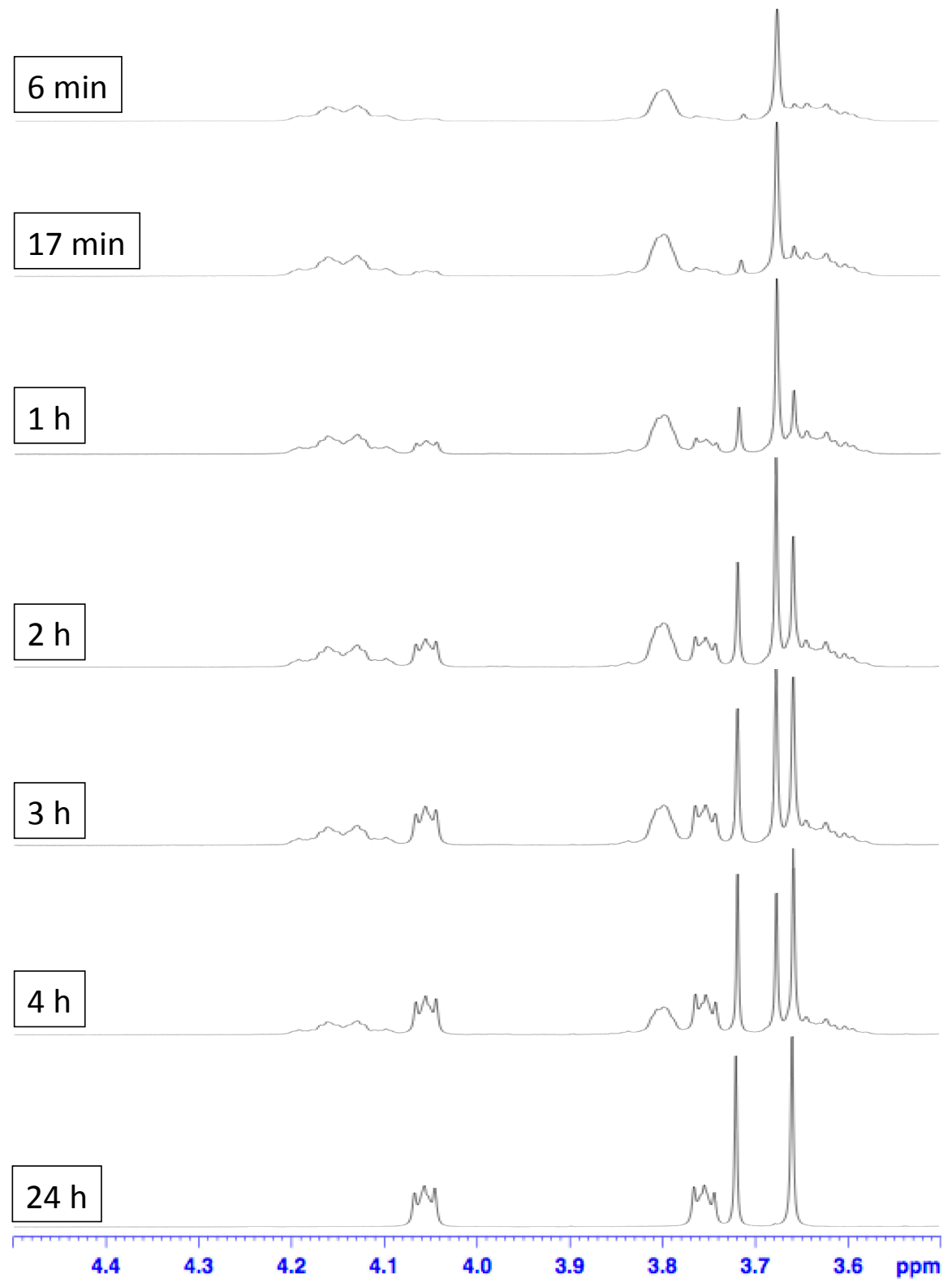

Figure 5. Stacked ${ }^{1} \mathrm{H}$ NMR spectra ( $400 \mathrm{MHz}, \mathrm{CD}_{3} \mathrm{SOCD}_{3}, 298 \mathrm{~K}$ ) showing the extrusion of DB24C8 macrocycle from the isolated [2]pseudorotaxane DB24C8 $\supset \mathbf{1}-\mathrm{H} \cdot \mathrm{PF}_{6}$ in DMSO- $d_{6}$ over time. 


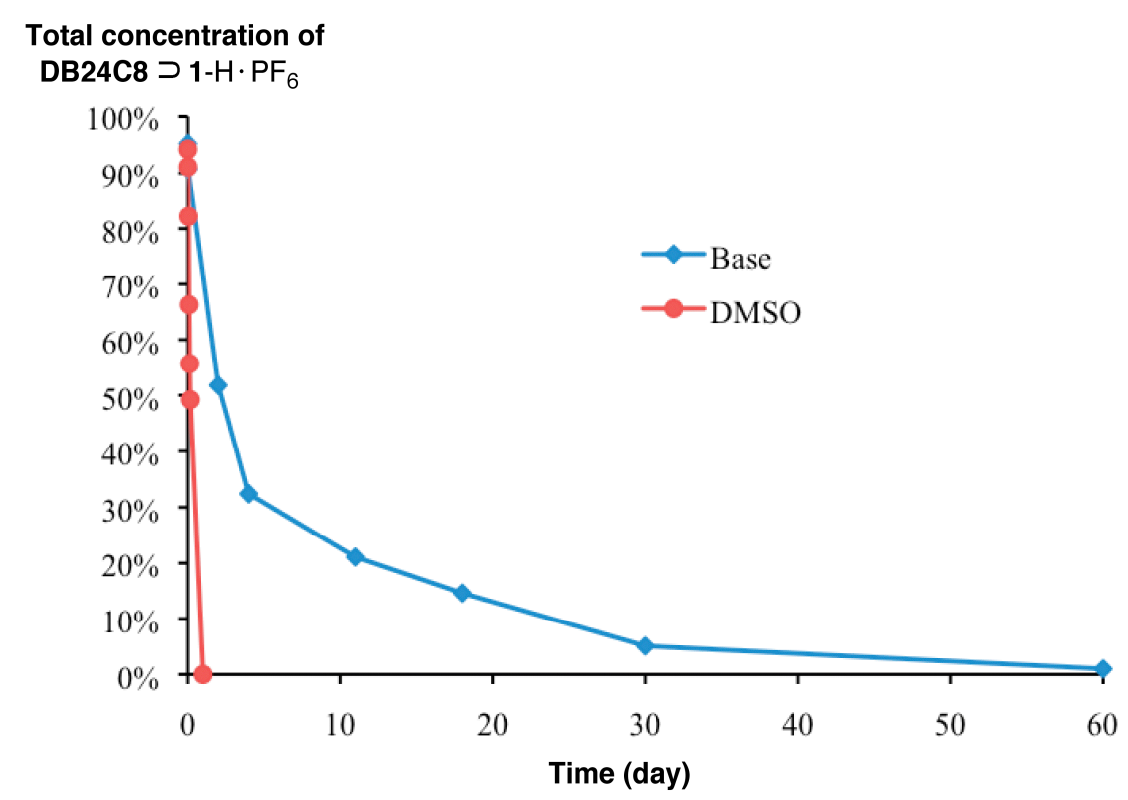

Figure 6. Dissociation data of the [2]pseudorotaxane DB24C8 $\supset 1-H \cdot P F_{6}$ in the presence of base and DMSO, characterized by ${ }^{1} \mathrm{H}$ NMR spectroscopy. A plot of the concentration (\%) of the [2]pseudorotaxane DB24C8 $\supset \mathbf{1}-\mathrm{H} \cdot \mathrm{PF}_{6}$ versus time (day).

\section{Experimental Section}

General Information. ${ }^{1} \mathrm{H}$ NMR (400 MHz) and ${ }^{13} \mathrm{C}$ NMR (100 MHz) spectra were recorded at room temperature in $\mathrm{CDCl}_{3}$ unless otherwise stated. Each solvent residual signal was used as the internal standard. Chemical shifts were reported as parts per million (ppm) in $\delta$ scale and coupling constants $(J)$ were reported in hertz. Mass spectra were obtained on a double focusing sector mass spectrometer with electrospray ionization (ESI) technique. The reported molecular mass $(\mathrm{m} / \mathrm{z})$ values, unless otherwise specified, were mono-isotopic mass. All reactions were carried out under $\mathrm{N}_{2}$. All reactions were monitored by thin layer chromatography (TLC) performed on pre-coated silica gel 60 $\mathrm{F}_{254}$ plates, and compounds were visualized with a spray of $5 \%(w / v)$ dodecamolybdophosphoric acid in ethanol and subsequent heating. Flash chromatography was carried out on columns of silica gel (230-400 mesh). Tetrahydrofuran (THF) was freshly distilled prior to use from sodium/benzophenone ketyl under $\mathrm{N}_{2}$. $\mathrm{CH}_{2} \mathrm{Cl}_{2}$ was freshly distilled from $\mathrm{CaH}_{2}$. Cyclohexanemethylamine (3) and dibenzo[24]crown-8 (DB24C8) were commercially available from Sigma-Aldrich (St. Louis, MO, USA) while the starting compound (2) was synthesized according to the literature procedures [39]. The synthetic scheme of new compounds is shown in Scheme 1.

Amide 4. 1-[3-(Dimethylamino)propyl]-3-ethylcarbodiimide methiodide (EDCI, $2.53 \mathrm{~g}, 8.52 \mathrm{mmol}$ ) was added to a stirred solution which contained 3-(3,5-dimethoxyphenyl)-propionic acid (2, $1.43 \mathrm{~g}$, $6.81 \mathrm{mmol})$, cyclohexanemethylamine $(3,1.00 \mathrm{~mL}, 7.69 \mathrm{mmol})$ and 1-hydroxybenzotriazole (HOBt) (1.14 g, $8.45 \mathrm{mmol})$ in $\mathrm{CH}_{2} \mathrm{Cl}_{2}(25 \mathrm{~mL})$. The reaction mixture was stirred for $18 \mathrm{~h}$ at $25{ }^{\circ} \mathrm{C}$ and concentrated under reduced pressure. The residue was purified by flash chromatography on silica gel (hexane/EtOAc $=4 / 1)$ to afford the amide (4) $(1.50 \mathrm{~g}, 72 \%)$ as a white solid. M.p.: $72.6-74.3{ }^{\circ} \mathrm{C}$. $R_{\mathrm{f}}: 0.58$ (hexane/EtOAc $\left.=4 / 1\right) .{ }^{1} \mathrm{H}$ NMR: $\delta 0.64-0.81\left(2 \mathrm{H}, \mathrm{m}, \mathrm{CH}_{2}\right), 0.92-1.14(3 \mathrm{H}, \mathrm{m}), 1.20-1.34$ $(1 \mathrm{H}, \mathrm{m}), 1.43-1.62(5 \mathrm{H}, \mathrm{m}), 2.38\left(2 \mathrm{H}, \mathrm{t}, J=7.6, \mathrm{CH}_{2} \mathrm{CH}_{2}\right), 2.77\left(2 \mathrm{H}, \mathrm{t}, J=7.6, \mathrm{CH}_{2} \mathrm{C}=\mathrm{O}\right), 2.92(2 \mathrm{H}$, 
$\left.\mathrm{t}, J=6.4, \mathrm{CHCH}_{2}\right), 3.60\left(6 \mathrm{H}, \mathrm{s}, \mathrm{CH}_{3}\right), 6.16(1 \mathrm{H}, \mathrm{s}, \mathrm{ArH}), 6.23(2 \mathrm{H}, \mathrm{s}, \operatorname{Ar} H), 6.61(1 \mathrm{H}, \mathrm{t}, J=5.2$, $\mathrm{NH}) .{ }^{13} \mathrm{C}$ NMR: $\delta 25.5,26.1,30.5,31.8,37.57,37.63,45.4,54.7,97.6,106.0,143.1,160.5,172.1$. ESI-MS: $m / z 328\left([\mathrm{M}+\mathrm{Na}]^{+}, 100 \%\right)$. HRESI-MS: calcd $m / z$ for $\mathrm{C}_{18} \mathrm{H}_{27} \mathrm{NO}_{3} \mathrm{Na}: 328.1883$, found: $328.1883\left([\mathrm{M}+\mathrm{Na}]^{+}, 100 \%\right)$.
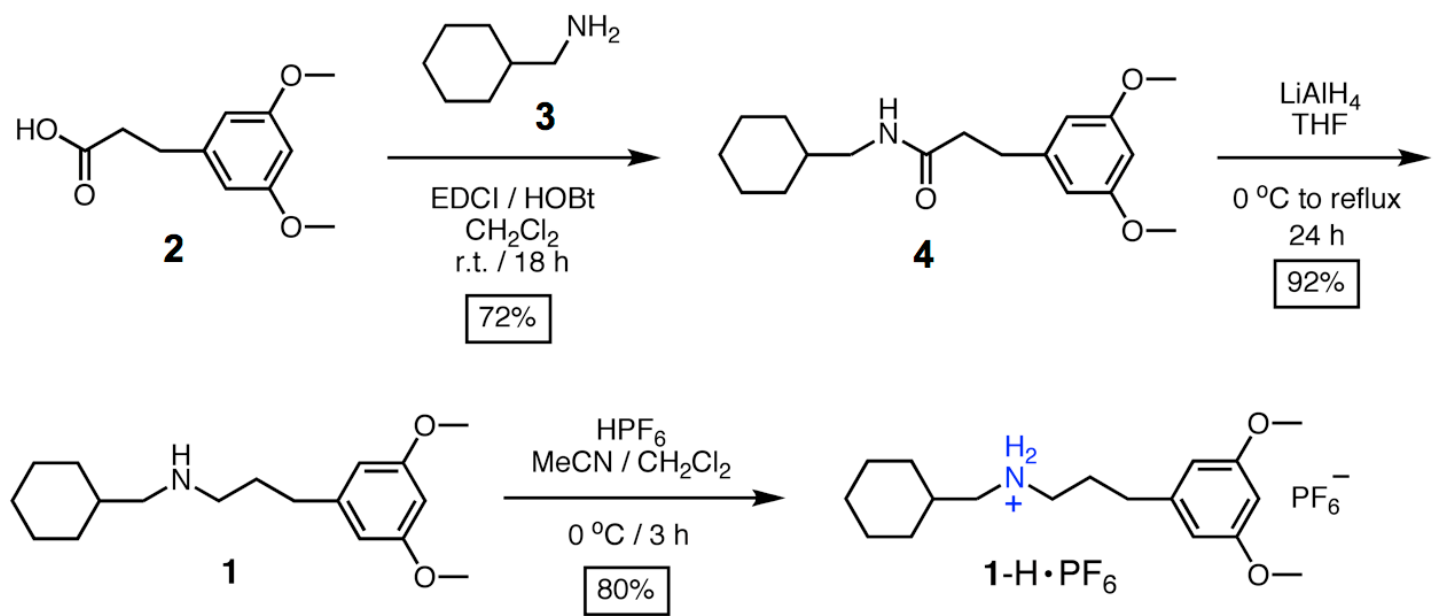

Scheme 1. Synthesis of the ammonium thread $1-\mathrm{H} \cdot \mathrm{PF}_{6}$.

Amine 1. Lithium aluminum hydride (LAH) $(0.77 \mathrm{~g}, 20.3 \mathrm{mmol})$ was added slowly to a stirred solution of amide (4) $(1.43 \mathrm{~g}, 4.68 \mathrm{mmol})$ in THF $(80 \mathrm{~mL})$ at $0{ }^{\circ} \mathrm{C}$. The solution was then heated to reflux for $24 \mathrm{~h}$. The solution was cooled down to room temperature and then poured into an ice-water mixture. The resultant mixture was then extracted with $\mathrm{CH}_{2} \mathrm{Cl}_{2}(50 \mathrm{~mL} \times 3)$ and the combined extracts were washed with brine, dried $\left(\mathrm{MgSO}_{4}\right)$, filtered and evaporated in vacuo to give the crude product which was purified by flash chromatography on silica gel (hexane/EtOAc/Et $3 \mathrm{~N}=240 / 120 / 1$ ) to afford the amine (1) $(1.25 \mathrm{~g}, 92 \%)$ as a colorless liquid. $R_{\mathrm{f}}$ : 0.35 (hexane/EtOAc/Et $\left.3 \mathrm{~N}=240 / 120 / 1\right) .{ }^{1} \mathrm{H} \mathrm{NMR}$ : $\delta$ 0.73-0.88 (2 H, m, CH $), 0.99-1.23(3 \mathrm{H}, \mathrm{m}), 1.28-1.42(1 \mathrm{H}, \mathrm{m}), 1.50-1.83(8 \mathrm{H}, \mathrm{m}), 2.34(2 \mathrm{H}, \mathrm{d}$, $\left.J=6.8, \mathrm{CHCH}_{2} \mathrm{NH}\right), 2.45-2.58\left(4 \mathrm{H}, \mathrm{m}, \mathrm{ArCH}_{2} \mathrm{CH}_{2}\right.$ and $\left.\mathrm{ArCH}_{2} \mathrm{CH}_{2}\right), 3.65\left(6 \mathrm{H}, \mathrm{s}, \mathrm{CH}_{3}\right), 6.20(1 \mathrm{H}, \mathrm{d}$, $J=2.0, \operatorname{Ar} H), 6.26(2 \mathrm{H}, \mathrm{d}, J=2.0, \operatorname{Ar} H) .{ }^{13} \mathrm{C} \mathrm{NMR}: \delta 25.8,26.4,31.1,31.2,33.7,37.6,49.3,54.8$, 56.4, 97.4, 106.1, 144.2, 160.5. ESI-MS: $\mathrm{m} / \mathrm{z} 292\left([\mathrm{M}+\mathrm{H}]^{+}, 100 \%\right)$. HRESI-MS: calcd $\mathrm{m} / z$ for $\mathrm{C}_{18} \mathrm{H}_{30} \mathrm{NO}_{2}: 292.2271$, found: $292.2276\left([\mathrm{M}+\mathrm{H}]^{+}, 100 \%\right)$.

Ammonium salt 1-H·PF . To a stirred solution of amine (1) $(1.25 \mathrm{~g}, 4.29 \mathrm{mmol})$ in a solvent mixture of $\mathrm{CH}_{3} \mathrm{CN} / \mathrm{CH}_{2} \mathrm{Cl}_{2}(3: 1)(20 \mathrm{~mL})$, excess hexafluorophosphoric acid $\left(\mathrm{HPF}_{6}\right)(1.20 \mathrm{~mL}$, $8.73 \mathrm{mmol}$ ) was added dropwise at $0{ }^{\circ} \mathrm{C}$. The reaction mixture was stirred for $3 \mathrm{~h}$ and then water $(12 \mathrm{~mL})$ was added to the mixture. The mixture was concentrated under reduced pressure and then extracted with $\mathrm{CH}_{2} \mathrm{Cl}_{2}(50 \mathrm{~mL} \times 3)$. The combined extracts were washed with brine, dried $\left(\mathrm{MgSO}_{4}\right)$, filtered and evaporated in vacuo to afford the ammonium salt $1-\mathrm{H} \cdot \mathrm{PF}_{6}(1.50 \mathrm{~g}, 80 \%)$ as a white solid. M.p.: $173.6-174.8{ }^{\circ} \mathrm{C} .{ }^{1} \mathrm{H}$ NMR $\left(\mathrm{CD}_{3} \mathrm{CN}\right): \delta 0.87-1.07$ (2 H, m, $\left.\mathrm{CH}_{2}\right), 1.08-1.34(3 \mathrm{H}, \mathrm{m}), 1.57-1.82$ $(6 \mathrm{H}, \mathrm{m}), 1.93-2.12\left(2 \mathrm{H}, \mathrm{m}, \mathrm{CH}_{2}\right), 2.61\left(2 \mathrm{H}, \mathrm{t}, J=7.6, \mathrm{ArCH}_{2}\right), 2.75-2.90\left(2 \mathrm{H}, \mathrm{m}, \mathrm{CHCH}_{2} \mathrm{NH}_{2}\right)$, 2.93-3.10 (2 H, m, $\left.\mathrm{CH}_{2} \mathrm{CH}_{2} \mathrm{NH}_{2}\right), 3.76\left(6 \mathrm{H}, \mathrm{s}, \mathrm{CH}_{3}\right), 6.34(1 \mathrm{H}, \mathrm{s}, \mathrm{ArH}), 6.41(2 \mathrm{H}, \mathrm{s}, \mathrm{ArH}), 6.61(2 \mathrm{H}$, br s, $\left.\mathrm{NH}_{2}\right) .{ }^{13} \mathrm{C} \mathrm{NMR}\left(\mathrm{CD}_{3} \mathrm{CN}\right): \delta 26.5,26.8,28.1,30.9,33.4,35.8,49.4,55.2,56.0,99.1,107.5,144.1$, 162.2. ESI-MS: $m / z 292$ ([M-PF6 $\left.]^{+}, 100 \%\right)$. HRESI-MS: calcd $m / z$ for $\mathrm{C}_{18} \mathrm{H}_{30} \mathrm{NO}_{2}: 292.2271$, found: $292.2265\left([\mathrm{M}-\mathrm{PF} 6]^{+}, 100 \%\right)$. 
Typical Synthesis of [2]Pseudorotaxane. A solution of 1- $\mathrm{H} \cdot \mathrm{PF}_{6}(17.5 \mathrm{mg}, 0.04 \mathrm{mmol})$ and DB24C8 (35.9 mg, $0.08 \mathrm{mmol})$ in a typical solvent $(1.5 \mathrm{~mL})$ was heated at 40 or $70{ }^{\circ} \mathrm{C}$ in a sealed tube for 4 days and then concentrated in vacuo. For an alternative method, a solution of $\mathbf{1}-\mathrm{H} \cdot \mathrm{PF}_{6}(120 \mathrm{mg}$, $0.27 \mathrm{mmol}$ ) and DB24C8 (40 mg, $0.089 \mathrm{mmol})$ in $\mathrm{MeCN}(3 \mathrm{~mL})$ was heated at $70{ }^{\circ} \mathrm{C}$ in a sealed tube for 4 days and then concentrated in vacuo. The resulting residue was purified by flash chromatography on silica gel $\left(\mathrm{CH}_{2} \mathrm{Cl}_{2} / \mathrm{THF}=7 / 1\right)$ to afford the [2]pseudorotaxane DB24C8 $\supset \mathbf{1}-\mathrm{H} \cdot \mathrm{PF}_{6}(34-36 \mathrm{mg}, 46 \%)$ as a white solid. M.p. was not determined due to thermal instability. $R_{\mathrm{f}}$ : $0.65\left(\mathrm{CH}_{2} \mathrm{Cl}_{2} / \mathrm{THF}=7 / 1\right)$. ${ }^{1} \mathrm{H}$ NMR $\left(\mathrm{CD}_{3} \mathrm{CN}\right): \delta$ 0.56-0.72 (2 H, m, CH 2$), 0.78-0.93(3 \mathrm{H}, \mathrm{m}), 1.40-1.55\left(6 \mathrm{H}, \mathrm{m}, \mathrm{CH}_{2}\right), 1.79-1.91$ $\left(2 \mathrm{H}, \mathrm{m}, \mathrm{CH}_{2}\right), 2.41\left(2 \mathrm{H}, \mathrm{t}, J=7.2, \mathrm{ArCH}_{2}\right), 3.08-3.18\left(2 \mathrm{H}, \mathrm{m}, \mathrm{CHCH}_{2} \mathrm{NH}_{2}\right), 3.27-3.38(2 \mathrm{H}, \mathrm{m}$, $\left.\mathrm{CH}_{2} \mathrm{CH}_{2} \mathrm{NH}_{2}\right), 3.58-3.70\left(8 \mathrm{H}, \mathrm{m}, \mathrm{CH}_{2} \mathrm{CH}_{2} \mathrm{OCH}_{2}\right), 3.72\left(6 \mathrm{H}, \mathrm{s}, \mathrm{CH}_{3}\right), 3.78-3.89(8 \mathrm{H}, \mathrm{m}$, $\left.\mathrm{ArOCH}_{2} \mathrm{CH}_{2}\right), 4.08-4.23\left(8 \mathrm{H}, \mathrm{m}, \mathrm{ArOCH}_{2} \mathrm{CH}_{2}\right), 6.16(2 \mathrm{H}, \mathrm{d}, J=2.0, \mathrm{Ar} H), 6.31(2 \mathrm{H}, \mathrm{d}, J=2.0$, $\mathrm{ArH}), 6.55-6.84\left(2 \mathrm{H}\right.$, br s, $\left.\mathrm{NH}_{2}\right), 6.90-7.02(8 \mathrm{H}, \mathrm{m}$, catechol $\mathrm{ArH}) .{ }^{13} \mathrm{C} \mathrm{NMR}\left(\mathrm{CD}_{3} \mathrm{CN}\right): \delta 26.1,26.5$, 28.7, 30.9, 33.4, 36.3, 49.2, 55.4, 55.9, 69.0, 71.3, 71.9, 98.7, 107.4, 113.6, 122.4, 144.0, 148.5, 162.0. ESI-MS: $m / z 740\left(\left[\mathrm{M}-\mathrm{PF}_{6}\right]^{+}, 100 \%\right)$. HRESI-MS: calcd $m / z$ for $\mathrm{C}_{42} \mathrm{H}_{62} \mathrm{NO}_{10}: 740.4368$, found: $740.4359\left(\left[\mathrm{M}-\mathrm{PF}_{6}\right]^{+}, 100 \%\right)$.

Typical [2]Pseudorotaxane Dissociation. For dissociation with bases, [2]pseudorotaxane DB24C8 $\supset$ 1-H $\cdot \mathrm{PF}_{6}(5 \mathrm{mg})$ was dissolved in $\mathrm{CD}_{3} \mathrm{CN}(0.7 \mathrm{~mL})$ in a NMR tube followed by the addition of 3 drops of $\mathrm{Et}_{3} \mathrm{~N}$ (TEA) and 3 drops of ${ }^{i} \operatorname{Pr}_{2} \mathrm{EtN}$ (DIPEA) to the solution. ${ }^{1} \mathrm{H}$ NMR spectra were recorded over time at $298 \mathrm{~K}$. For dissociation with solvent, [2]pseudorotaxane DB24C8 $\supset \mathbf{1}-\mathrm{H} \cdot \mathrm{PF}_{6}$ (5 mg) was dissolved in $\mathrm{CD}_{3} \mathrm{SOCD}_{3}(0.7 \mathrm{~mL})$ in a NMR tube. ${ }^{1} \mathrm{H}$ NMR spectra were recorded over time at $298 \mathrm{~K}$.

\section{Conclusions}

In summary, a [2]pseudorotaxane DB24C8 $\supset$ 1-H $\cdot \mathrm{PF}_{6}$ which was synthesized and isolated from a slippage approach, was found to be stable at room temperature. The [2]pseudorotaxane DB24C8 $\supset 1-H \cdot P_{6}$ was characterized by NMR spectroscopy and mass spectrometry. The dissociation rate of [2]pseudorotaxane DB24C8 $\supset \mathbf{1}-\mathrm{H} \cdot \mathrm{PF} 6$ could be tuned by amine bases and DMSO solvent at room temperature from which the supramolecular interactions between the crown ether DB24C8 and the ammonium can be tuned. When the crown ether DB24C8 was lost its noncovalent interactions with the ammonium/amine, it could be detached from the dumbbell 1-H·PF 6 via the molecular flipping of between the chair-boat-chair forms of the cyclohexyl ring. In particular, the dissociation of [2]pseudorotaxane DB24C8 $\supset \mathbf{1}-\mathrm{H} \cdot \mathrm{PF}_{6}$ with amine bases possessed a long and sustained, complete dissociation over 60 days. The use of DMSO possessed relatively fast and complete dissociation $(24 \mathrm{~h})$. The selectively tunable dissociation rates by potentially varying the ratios of stimuli for macrocycle extrusion from the novel [2]pseudorotaxane provide avenues for constructing novel functional nanovalves that sustained release substrates for a much longer period of time.

\section{Acknowledgments}

We acknowledge the financial support by the General Research Fund (201213) by the Research Grants Council of Hong Kong. This work is also partially supported by a grant from the University Grants Committee of HKSAR (Area of Excellence Scheme AoE/P-03/08). 


\section{Author Contributions}

Conceived and designed the experiments: Ken Cham-Fai Leung, Kwun-Ngai Lau, Wing-Yan Wong. Performed the experiments: Kwun-Ngai Lau, Wing-Yan Wong. Analyzed the data: Ken Cham-Fai Leung, Kwun-Ngai Lau, Wing-Yan Wong. Contributed reagents/materials/analysis tools: Ken Cham-Fai Leung. Contributed to the writing of the manuscript: Ken Cham-Fai Leung, and Wing-Yan Wong.

\section{Conflicts of Interest}

The authors declare no conflict of interest.

\section{References}

1. Ashton, P.R.; Baxter, I.; Fyfe, M.C.T.; Raymo, F.M.; Spencer, N.; Stoddart, J.F.; White, A.J.P.; Williams, D.J. Rotaxane or Pseudorotaxane? That Is The Question! J. Am. Chem. Soc. 1998, 120, 2297-2307.

2. Affeld A.; Hübner G.M.; Seel, C.; Schalley, C.A. Rotaxane or Pseudorotaxane? Effects of Small Structural Variation on the Deslipping Kinetics of Rotaxanes with Stopper Groups of Intermediate Size. Eur. J. Org. Chem. 2001, 2001, 2877-2890.

3. Aricó, F.; Badjic, J.D.; Cantrill, S.J.; Flood, A.H.; Leung, K.C.-F.; Liu Y.; Stoddart, J.F. Templated Synthesis of Interlocked Molecules. Top. Curr. Chem. 2005, 249, 203-259.

4. Hirose, K.; Nakamura, Y.; Tobe, Y. Remarkable Effects of Chirality on Deslipping Reactions of Diasteromeric Rotaxanes and Relevant Mechanism Involving Pre-Equilibrium. Org. Lett. 2009, $11,145-147$.

5. Leung, K.C.-F.; Chak, C.-P.; Lo, C.-M.; Wong, W.-Y.; Xuan S.; Cheng, C.H.K. pH-Controllable Supramolecular Systems. Chem. Asian J. 2009, 4, 364-381.

6. Wong, W.-Y.; Lee, S.-F.; Chan, H.-S.; Mak, T.C.M.; Wong, C.-H.; Huang L.-S.; Stoddart, J.F.; Leung, K.C.-F. Recognition between V- and Dumbbell-shaped Molecules. RSC Adv. 2013, 3, 26382-26390.

7. Nijhuis, C.A.; Ravoo, B.J.; Huskens J.; Reinhoudt, D.N. Redox-active Supramolecular Systems. Coord. Chem. Rev. 2007, 251, 1761-1780.

8. Liu, Y.; Flood A. H.; Stoddart, J.F. Thermally and Electrochemically Controllable Self-Complexing Molecular Switches. J. Am. Chem. Soc. 2004, 126, 9150-9151.

9. Fernando, I.R.; Bairu, S.G.; Guda, R.; Mezei, G. Single-Color Pseudorotaxane-based Temperature Sensing. New J. Chem. 2010, 34, 2097-2100.

10. Leung, K.C.-F.; Wong, W.-Y.; Aricó, F.; Haussmann P.C.; Stoddart, J.F. The Stability of Imine-containing Dynamic [2]Rotaxane to Hydrolysis. Org. Biomol. Chem. 2010, 8, 83-89.

11. Wong, W.-Y.; Leung K.C.-F.; Stoddart, J.F. Self-assembly, Stability Quantification, Controlled Molecular Switching, and Sensing Properties of an Anthracene-containing Dynamic [2]Rotaxane. Org. Biomol. Chem. 2010, 8, 2332-2343.

12. Leung, K.C.-F.; Nguyen, T.D.; Stoddart, J.F.; Zink, J.I. Supramolecular Nanovalves Controlled by Proton Abstraction and Competitive Binding. Chem. Mater. 2006, 18, 5919-5928. 
13. Saha, S.; Leung, K.C.-F.; Nguyen, T.D.; Stoddart J.F.; Zink, J.I. Nanovalves. Adv. Funct. Mater. 2007, 17, 685-693.

14. Cotí, K.K.; Belowich, M.E.; Liong, M.; Ambrogio, M.W.; Lau, Y.A.; Khatib, H.A.; Zink, J.I.; Khashab, N.M.; Stoddart, J.F. Mechanised Nanoparticles for Drug Delivery. Nanoscale 2009, 1, $16-39$.

15. Rowan, S.J.; Cantrill, S.J.; Cousins, G.R.L.; Sanders, J.K.M.; Stoddart, J.F. Dynamic Covalent Chemistry. Angew. Chem. Int. Ed. 2002, 41, 898-952.

16. Grigoras, M.; Catanescu, C.O. Imine Oligomers and Polymers. J. Macromol. Sci. Polym. Rev. 2004, C44, 131-173.

17. Meyer, C.D.; Joiner, C.S.; Stoddart, J.F. Template-directed Synthesis Employing Reversible Imine Bond Formation. Chem. Soc. Rev. 2007, 36, 1705-1723.

18. Haussmann, P.C.; Stoddart, J.F. Synthesizing Interlocked Molecules Dynamically. Chem. Rec. 2009, 9, 136-154.

19. Herrmann, A. Dynamic Mixtures and Combinatorial Libraries: Imines as Probes for Molecular Evolution at the Interface between Chemistry and Biology. Org. Biomol. Chem. 2009, 7, 3195-3204.

20. Maeda, T.; Otsuka, H.; Takahara, A. Dynamic Covalent Polymers: Reorganizable Polymers with Dynamic Covalent Bonds. Prog. Polym. Sci. 2009, 34, 581-604.

21. Klivansky, L.M.; Koshkakaryan, G.; Cao, D.; Liu, Y. Linear pi-acceptor-templated Dynamic Clipping to Macrobicycles and [2]Rotaxanes. Angew. Chem. Int. Ed. 2009, 48, 4185-4189.

22. Yin, J.; Dasgupta, S.; Wu, J. Template-directed Synthesis of Rotaxanes by Clipping: The Effect of the Dialkylammonium Recognition Sites. Org. Lett. 2010, 12, 1712-1715.

23. Leung, K.C.-F.; Lau, K.-N. Self-assembly and Thermodynamic Synthesis of Rotaxane Dendrimers and Related Structures. Polym. Chem. 2010, 1, 988-1000.

24. Ho, W.K.-W.; Lee, S.-F.; Wong, C.-H.; Zhu, X.-M.; Kwan, C.-S.; Chak, C.-P.; Mendes, P.M.; Cheng, C.H.K.; Leung, K.C.-F. Type III-B Rotaxane Dendrimers. Chem. Commun. 2013, 49, 10781-10783.

25. Harrison, I.T. The Effect of Ring Size on Threading Reactions of Macrocycles. J. Chem. Soc. Chem. Commun. 1972, 231-232.

26. Raymo, F.M.; Stoddart, J.F. Slippage-A Simple and Efficient Way to Self-assemble [n]Rotaxanes. Pure Appl. Chem. 1997, 69, 1987-1997.

27. Elizarov, A.M.; Chang, T.; Chiu, S.-H.; Stoddart, J.F. Self-assembly of Dendrimers by Slippage. Org. Lett. 2002, 4, 3565-3568.

28. Hsueh, S.-Y.; Lai, C.-C.; Liu, Y.-H.; Wang, Y.; Peng, S.-M.; Chiu, S.-H. Protecting a Squaraine Near-IR Dye Through Its Incorporation in a Slippage-derived [2]Rotaxane, Org. Lett. 2007, 9, 4523-4526.

29. Schill, G. Catenanes, Rotaxanes, and Knots; Academic Press: New York, NY, USA, 1971; p.3.

30. McConnell, A.J.; Beer, P.D. Kinetic Studies Exploring the Role of Anion Templation in the Slippage Formation of Rotaxane-Like Structures. Chem. Eur. J. 2011, 17, 2724-2733.

31. Zhang, M.; Xu, D.; Yan, X.; Chen, J.; Dong, S.; Zheng, B.; Huang, F. Self-Healing Supramolecular Gels Formed by Crown Ether Based Host-Guest Interactions. Angew. Chem. Int. Ed. 2012, 51, 7011-7015. 
32. Wang, F.; Han, C.; He, C.; Zhou, Q.; Zhang, J.; Wang, C.; Li, N.; Huang, F. Self-sorting Organization of Two Heteroditopic Monomers to Supramolecular Alternating Copolymers. J. Am. Chem. Soc. 2008, 130, 11254-11255.

33. Ji, X.; Yao, Y.; Li, J.; Yan, X.; Huang, F. A Supramolecular Cross-linked Conjugated Polymer Network for Multiple Fluorescent Sensing. J. Am. Chem. Soc. 2013, 135, 74-77.

34. Dong, S.; Zheng, B.; Xu, D.; Yan, X.; Zhang, M.; Huang, F. A Crown Ether Appended Super Gelator with Multiple Stimulus Responsiveness. Adv. Mater. 2012, 24, 3191-3195.

35. Dong, S.; Luo, Y.; Yan, X.; Zheng, B.; Ding, X.; Yu, Y.; Ma, Z.; Zhao, Q.; Huang, F. A Dual-Responsive Supramolecular Polymer Gel Formed by Crown Ether Based Molecular Recognition. Angew. Chem. Int. Ed. 2011, 50, 1905-1909.

36. Cantrill, S.J.; Fulton, D.A.; Heiss, A.M.; Pease, A.R.; Stoddart, J.F.; White, A.J.P.; Williams, D.J. The Influence of Macrocyclic Polyether Constitution Upon Ammonium Ion/Crown Ether Recognition Processes. Chem. Eur. J. 2000, 6, 2274-2287.

37. Bolla, M.A.; Tiburcio, J.; Loeb, S.J. Characterization of a Slippage Stopper for the 1,2-Bis(pyridinium)ethane-[24]crown-8 ether [2]Pseudorotaxane Motif. Tetrahedron 2008, 64, 8423-8428.

38. Linnartz, P.; Bitter, S.; Schalley, C.A. Deslipping of Ester Rotaxanes: A Cooperative Interplay of Hydrogen Bonding with Rotational Barriers. Eur. J. Org. Chem. 2003, 24, 4819-4829.

39. Bauta, W.E.; Lovett, D.P.; Cantrell, W.R.; Burke, B.D. Formal Synthesis of Angiogenesis Inhibitor NM-3. J. Org. Chem. 2003, 68, 5967-5973.

(C) 2015 by the authors; licensee MDPI, Basel, Switzerland. This article is an open access article distributed under the terms and conditions of the Creative Commons Attribution license (http://creativecommons.org/licenses/by/4.0/). 